\title{
LETTER
}

\section{Heparin algorithm for anticoagulation during continuous renal replacement therapy}

\author{
Marlies Ostermann*, Helen Dickie, Linda Tovey and David Treacher
}

\begin{abstract}
Premature circuit clotting is a problem during continuous renal replacement therapy. We describe an algorithm for individualised anticoagulation with unfractionated heparin based on the patient's risk of bleeding and previous circuit life. The algorithm allows effective and safe nurse-led anticoagulation during continuous renal replacement therapy.
\end{abstract}

\section{Introduction}

Continuous renal replacement therapy (CRRT) has become an established treatment for patients with acute kidney injury in the intensive care unit (ICU). Premature circuit clotting is a common problem, leading to reduced circuit life, to reduced clearance and also to increased blood loss, work load and cost of therapy [1]. There are different ways of maintaining the circuit patent [2]. An international questionnaire showed that in the UK more than $98 \%$ of ICUs surveyed used unfractionated heparin [3]. The major advantages of unfractionated heparin are the low costs, familiarity, ease of administration and reversibility with protamine. CRRT is predominantly nurse-led [4]. After a decision is made to start CRRT, nurses usually prepare and manage the technique.

Unfractionated heparin is the first-line anticoagulant in our unit. In order to enable the nursing staff to manage CRRT effectively and safely, we aimed to have clear guidelines in place, including an algorithm for the use of heparin.

\section{Methods}

We contacted seven large ICUs in the UK and three units outside the UK. None of the ICUs contacted had a guideline for the use of unfractionated heparin during CRRT. We therefore designed an algorithm based on data

${ }^{*}$ Correspondence: Marlies.Ostermann@gstt.nhs.uk

Guy's \& St Thomas' Foundation Trust, Department of Critical Care, Westminster Bridge Road, London SE17EH, UK from the literature and our own clinical experience (Figure 1).

\section{Results}

The principles of the algorithm (Figure 1) are as follows. First, unfractionated heparin is administered via the circuit. Second, heparin is administered into the circuit priming solution before the blood is in contact with plastic surfaces $(10,000 \mathrm{iu}$ heparin/1,000 $\mathrm{ml}$ of $0.9 \%$ $\mathrm{NaCl}$ ). Third, the dose of heparin is based on the patient's body weight. Fourth, the starting dose of heparin is individualised depending on the risk of bleeding and the previous circuit life - subsequent doses can be adjusted by the nursing staff according to the algorithm without the need for a medical review. Fifth, there is no target activated partial thromboplastin time ratio but this ratio is kept $\leq 2$ to prevent over-anticoagulation. Sixth, regular attention is paid to nonpharmacological methods to maintain circuit patency (that is, change of vascular access, blood flow, predilution/postdilution ratio).

A recent audit covering the period May 2008 to May 2009 confirmed a mean circuit life of 19.8 hours using unfractionated heparin without any untoward incidents.

Copies of our algorithm have already been requested by several ICUs in the UK. The aim of the present paper is therefore to share our practice more widely.

\section{Conclusion}

Our heparin algorithm allows nurse-led effective and safe anticoagulation with unfractionated heparin during CRRT.

\section{Abbreviations}

CRRT, continuous renal replacement therapy; ICU, intensive care unit.

\section{Acknowledgements}

The authors would like to thank Ms Sam Lippett, former ICU pharmacist at Guy's \& St Thomas' Hospital, for her contribution. The project was supported by internal departmental funds.

\section{Competing interests}

The authors declare that they have no completing interests.

Published: 27 May 2010 


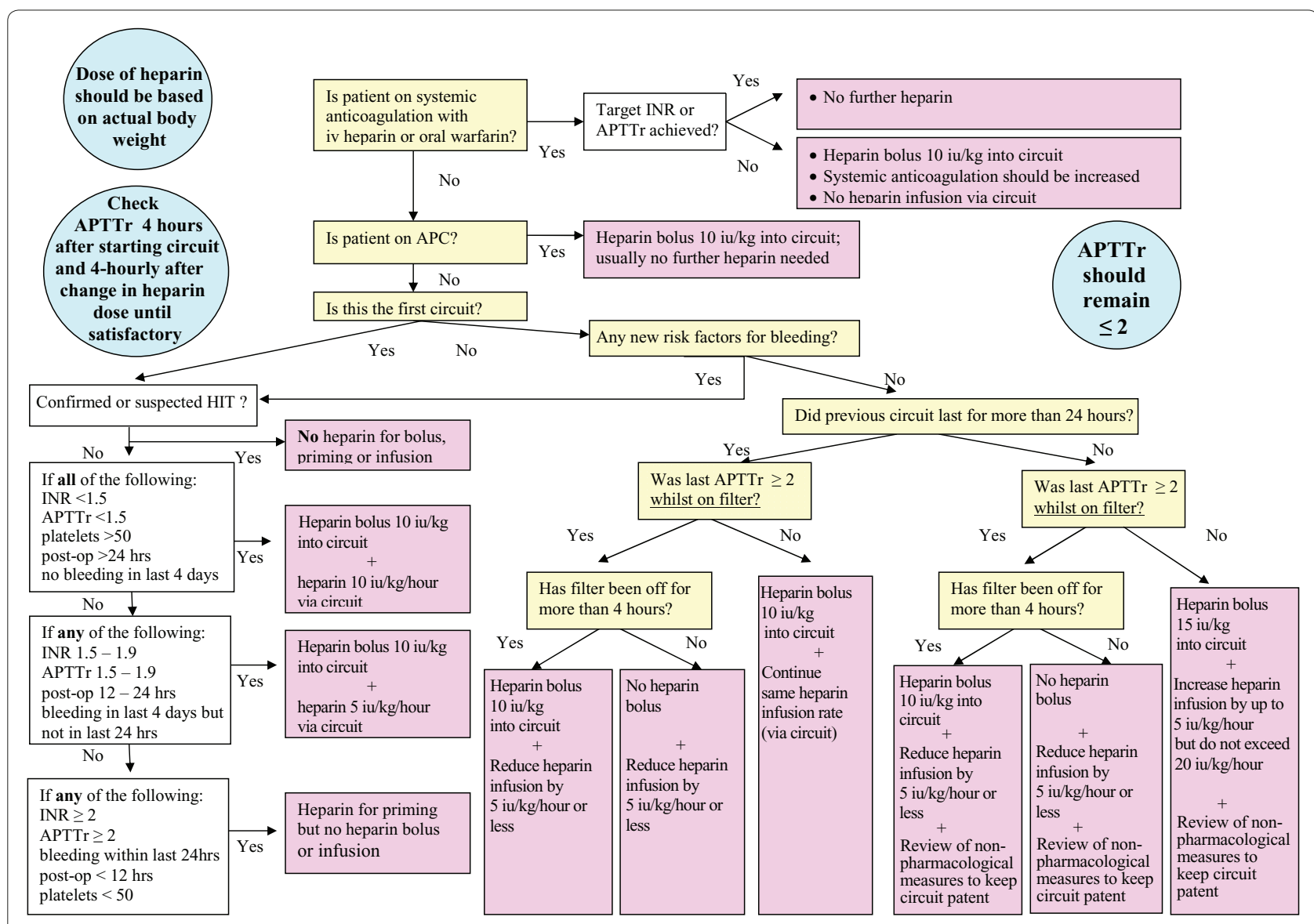

Figure 1. Algorithm for heparin anticoagulation during continuous renal replacement therapy. Algorithm is based on using 10,000 iu heparin in $40 \mathrm{ml}$ of $0.9 \% \mathrm{NaCl}$. APC, activated protein C; APTTr, activated partial thromboplastin time ratio; CRRT, continuous renal replacement therapy; HIT, heparin-induced thrombocytopenia; INR, international normalised ratio; iv, intravenous; post-op, postoperative.

\section{References}

1. Baldwin I: Factors affecting circuit patency and filter 'life'. Contrib Nephrol 2007, 156:178-184

2. Joannidis M, Oudemans-van Straaten HM: Clinical review: Patency of the circuit in continuous renal replacement therapy. Crit Care 2007, 11:218.

3. Wright SE, Bodenham A, Short AIK, Turney JH: The provision and practice of renal replacement therapy on adult intensive care units in the United Kingdom. Anaesthesia 2003, 58:1063-1069.

4. Baldwin I, Fealy N: Clinical nursing for the application of continuous renal replacement therapy in the intensive care unit. Semin Dial 2009 22:189-193.

doi:10.1186/cc9003

Cite this article as: Ostermann $M$, et al:: Heparin algorithm for

anticoagulation during continuous renal replacement therapy. Critical Care 2010, 14:419. 